\title{
The Evaluation of Flow Mediated Dilatation and Blood Parameters in Raynaud Phenomenon
}

\author{
Suheyla UZUN ${ }^{1}$ and Ilker KAYA ${ }^{2}$ \\ ${ }^{1}$ Tokat Gaziosmanpaşa University \\ ${ }^{2}$ Tokat State Hospital
}

August 5, 2021

\begin{abstract}
Introduction: Raynaud phenomenon (RP) is a multifactorial disorder. If any underlying disease cannot be detected responsible for RP then it considered as primary RP (pRP). We aimed to investigate the differences between laboratory markers and impaired endothelial function in pRP. Material and Methods: Forty-two pRP patients included as study and control groups were created from 30 healthy individuals. The endothelial function was evaluated with flow-mediated dilatation (FMD) of the brachial artery. The blood samples were obtained both groups and white blood cell [WBC], hemoglobin, platelet, mean platelet volume $[\mathrm{MPV}]$, creatinine, alanine aminotransferase $[\mathrm{ALT}]$, aspartate aminotransferase[AST], D-dimer, fibrinogen, albumin, fibrinogen to albumin ratio [FAR], Neutrophil to Lymphocyte ratio [NLR], D-dimer to albumin ratio [DDAR] and monocyte chemo-attractant protein-1 [MCP-1]. Obtained blood parameters and FMD values were compared between groups. Results: The groups were found as similar in regards to age, gender, smoking history $(\mathrm{p}<0.05)$. There was no difference between the two groups in regards to hemoglobin, platelet, MPV, creatinine, ALT, D-dimer, albumin, FAR, NLR, DDAR levels (p<0.05). AST levels were slightly higher in pRP group $(\mathrm{p}=0.027)$. Markedly increased WBC, fibrinogen, MPV and MCP-1 values were detected in $\mathrm{pRP}$ group $(\mathrm{p}=0.000)$. Additionally, higher abnormal FMD responses were detected in $\mathrm{pRP}$ group $(\mathrm{p}=0.000)$. There was a direct correlation between abnormal FMD response and serum MCP-1 values in patients with pRP (R: 0.308, R2: 0.095, p: 0.044). Conclusion: It seems to be that MCP-1 levels are higher in patients with pRP and increased values of MCP-1 levels seem to be related to impaired endothelial functions
\end{abstract}

The Evaluation of Flow Mediated Dilatation and Blood Parameters in Raynaud Phenomenon Running Title: Possible Predictors of Raynaud Disease

\begin{abstract}
Introduction: Raynaud phenomenon $(\mathrm{RP})$ is a multifactorial disorder. If any underlying disease cannot be detected responsible for RP then it considered as primary RP (pRP). We aimed to investigate the differences between laboratory markers and impaired endothelial function in pRP.

Material and Methods: Forty-two pRP patients included as study and control groups were created from 30 healthy individuals. The endothelial function was evaluated with flow-mediated dilatation (FMD) of the brachial artery. The blood samples were obtained both groups and white blood cell [WBC], hemoglobin, platelet, mean platelet volume [MPV], creatinine, alanine aminotransferase [ALT], aspartate aminotransferase[AST], D-dimer, fibrinogen, albumin, fibrinogen to albumin ratio [FAR], Neutrophil to Lymphocyte ratio [NLR], D-dimer to albumin ratio [DDAR] and monocyte chemo-attractant protein-1 [MCP-1]. Obtained blood parameters and FMD values were compared between groups.
\end{abstract}


Results: The groups were found as similar in regards to age, gender, smoking history $(\mathbf{p}<0.05)$. There was no difference between the two groups in regards to hemoglobin, platelet, MPV, creatinine, ALT, D-dimer, albumin, FAR, NLR, DDAR levels $(\mathbf{p}<0.05)$. AST levels were slightly higher in pRP group $(\mathrm{p}=\mathbf{0 . 0 2 7})$. Markedly increased WBC, fibrinogen, MPV and MCP-1 values were detected in pRP group $(\mathrm{p}=0.000)$. Additionally, higher abnormal FMD responses were detected in $\mathrm{pRP}$ group $(\mathrm{p}=0.000)$. There was a direct correlation between abnormal FMD response and serum MCP-1 values in patients with pRP (R: 0.308, R2: 0.095, p: 0.044).

Conclusion: It seems to be that MCP-1 levels are higher in patients with pRP and increased values of MCP-1 levels seem to be related to impaired endothelial functions

Key Words: Primary Raynaud phenomenon, blood parameters, monocyte chemoattractant protein-1, endothelial function, flow mediated dilatation

\section{What's already known about this topic?}

Raynaud's phenomenon (RP) is a reversible vasospastic disorder that may be provoked by cold or emotional stress. This phenomenon can be occur without underlying disease or unknown etiology which named as primary RP (pRP). The essential finding of $\mathrm{pRP}$ is aggravation of symptoms by exposure cold and the detection of color changes (turn white, blue, or both). The diagnosis is clarified after exclusion of possible underlying diseases with checking nail capillaroscopy and laboratory panel such as complete blood counting, inflammatory parameters, metabolic panel, antibodies, enzymes etc. However, any specific laboratory marker was not determined for diagnosing $\mathrm{pRP}$. Therefore, researchers tried to determine an objective laboratory marker that is highly specific and scientific for pRP.

What does this article add?

To best of our knowledge this is the first study about relationship between FMD response (impaired endothelial response) and blood parameters in patients with pRP. On the other hand this is the first report about relationship between impaired endothelial response and MCP-1 levels in pRP. Our results indicated that patients with pRP have higher impaired endothelial to ischemia. The incremental levels of serum WBC, MPV, MCP-1 and fibrinogen values were detected in pRP group. Moreover, moderate direct correlation was found between abnormal FMD response and serum MCP-1 values.

\section{INTRODUCTION}

Raynaud's phenomenon (RP) is a reversible vasospastic disorder that may be provoked by cold or emotional stress. RP involves extremity arteries and presented with ischemic symptoms of extremities ${ }^{1}$. RP can be preliminary finding of some diseases and called as secondary RP (sRP). This disorder can be related with traumas or micro-traumas (prolonged usage of vibratory tools), exposure of some chemicals and auto immune rheumatic or connective tissue diseases (such as systemic sclerosis). If it is progressed it can be resulted with digital ulcers or micro-amputations ${ }^{1-3}$. However, RP can be occur without underlying disease or unknown etiology which named as primary RP (pRP). This sort of $\mathrm{pRP}$ commonly littered with atmospheric condition and therefore the symptoms reliefs dramatically when exposure to the cause is removed ${ }^{4,5}$. In primary type, there is no autoimmunity associated marker or reaction. Therefore, a comprehensive anamnesis should be taken and physical and laboratory examination should be made in every case with RP and after excluding suspected pathologies the RP are often classified as primary type ${ }^{1,5}$.

The essential finding of pRP is aggravation of symptoms by exposure cold and the detection of color changes (turn white, blue, or both). The diagnosis is clarified after exclusion of possible underlying diseases with checking nail capillaroscopy and laboratory panel such as complete blood counting, inflammatory parameters, metabolic panel, antibodies, enzymes etc. Avoiding contact with cold and stress is suggested for these patients. Lifestyle changes such as reducing smoking and caffeine use are important. Additionally, some medications can be applied ${ }^{1-5}$. However, some patients have borderline symptoms without physical findings like sort of a feeling of cold within the extremities. In this patient group, management is harder because no 
finding apart from anamnesis has been determined, and no parameter has been defined for possible suspicion 6,7 . Especially, an abnormal capillaroscopic finding for differentiation of RP is discriminative for secondary RP. Thus, nailfold capillaroscopy is losing potential predictor role for pRP.

The aim of this study was to investigate the possible predictors for pRP. Therefore, flow-mediated dilatation (FMD), routine blood markers, and monocyte chemoattractant protein-1 (MCP1) levels were compared between pRP patients and healthy individuals.

\section{MATERIAL AND METHOD}

The study steps were designed according to the Declaration of Helsinki and ethical approval was obtained from the Local Ethics Committee of the University. The signed informed consent was obtained from all participants. This study was designed as a prospective, case-control study.

Patients over 50 years of age (because of increased risk of atherosclerotic occlusive arterial diseases), with past medical history with trauma, thoracic outlet syndrome, secondary RP (malignity, vasculitis, systemic inflammatory disease, auto-immune diseases, etc.), anti-inflammatory or corticosteroid usage history, and patients with accompanying diabetes, hypertension, familial hyperlipidemia were excluded from the study.

After exclusion of secondary RP, a total of 43 patients was included in the study who admitted to the cardiovascular surgery clinic with RP symptoms (bruising and cold hands/f provoked by cold) and diagnosed as primary RP (Figure 1). The control group was formed from healthy individuals who admitted to the hospital for a routine checkup without cardiovascular symptoms.

\section{Evaluation of flow-mediated dilatation (FMD)}

The FMD evaluation was made in each participant in early morning after overnight fasting period in a standard ultrasound room by expert sonographer before starting other steps of study (blood sampling) as described in previous literature ${ }^{8,9}$. An android compatible linear transducer (Philips Lumify L12-4 [12-4 $\mathrm{mHz}$; Philips Ultrasound Inc., Bothell, WA) was used to evaluation of vessel diameter. The normal diameter of the brachial artery was measured over about $5 \mathrm{~cm}$ of the antecubital fossa and therefore the evaluation point was marked. Thereafter the sphygmomanometer cuff was placed to proximal site of evaluation point and inflated to above $50 \mathrm{mmHg}$ of normal blood pressure for five minutes as explained in previous literature ${ }^{8,9}$ . After 5 minutes of ischemia period cuff was deflated and the ultrasound probe was placed to marked point for measurement of post-ischemic diameter of brachial artery. The enlargement of diameter equal or over than $5 \%$ was accepted as normal response and lower than $5 \%$ was accepted as abnormal vascular response to ischemia which indicates abnormal endothelial function ${ }^{8,9}$.

\section{Blood Sampling}

After evaluation of the FMD response the routine $10 \mathrm{ml}$ venous blood samples were obtained from each participant. After centrifugation, routine laboratory parameters (white blood cell [WBC] $\left(10^{-3} / \mathrm{uL}\right)$, hemoglobin $(\mathrm{g} / \mathrm{dL})$, platelet $\left(10^{-3} / \mathrm{uL}\right)$, mean platelet volume $[\mathrm{MPV}](\mathrm{fL})$, creatinine $(\mathrm{mg} / \mathrm{dL})$, alanine aminotransferase [ALT] (IU/L), aspartate aminotransferase[AST] (IU/L), D-dimer $(\mathrm{ng} / \mathrm{L})$, fibrinogen $(\mu \mathrm{g} / \mathrm{ml})$, albumin $(\mathrm{g} / \mathrm{dL})$, fibrinogen to albumin ratio [FAR] (\%), Neutrophil to Lymphocyte ratio [NLR] (\%), D-dimer to albumin ratio [DDAR] (\%)) and monocyte chemo-attractant protein-1 [MCP-1] (pg/ml) levels were studied from obtained serum samples. The commercially available human MCP1 ELISA kit (SUNLONG, Sun Long Biotech Co., LTD) was used for determining MCP-1 levels (SUNLONG, Sun Long Biotech Co., LTD) as described in previous reports ${ }^{10}$.

\section{Statistical Analyze}

The nominal data analysis was made by using Yates- corrected chi-square test. A comparison of parametric data between the two groups was made by using student tests. Pearson correlation coefficients were used to compare the relation of parameters with FMD. SPSS 17.0 (SPSS Inc., Chicago, IL, USA) statistical software program was used for all statistical analyses. A p-value less than 0.05 was considered significant. 


\section{RESULTS}

The groups were found as similar $(\mathrm{p}>0.05)$ in regards of demographical variables (age, gender, smoking) and markedly higher abnormal FMD responses rates detected in primary RP patient group $(\mathrm{p}=0.000)$. The comparison of demographical, clinical (FMD) and laboratory variables between control and pRP patients was demonstrated in Table 1.

Serum hemoglobin, platelet, creatinine, ALT, D-Dimer, FAR, NLR, albumin, DDAR values were found as similar between groups $(\mathrm{p}>0.05)$. Slightly higher AST values $(\mathrm{p}=0.027)$ were detected in $\mathrm{pRP}$ group $(25.60 \pm 9.77 \mathrm{IU} / \mathrm{L})$ when compare with healthy subjects $(21.20 \pm 5.14 \mathrm{IU} / \mathrm{L})$. Serum WBC, MPV, fibrinogen and MCP-1 values were significantly higher in pRP group (Table 1) when compare with healthy control group $(\mathrm{p}<0.05)$.

Higher MCP-1 values (Figure 2) were detected in participants with abnormal FMD response $(\mathrm{p}=0.001)$. The significant correlation was detected between abnormal FMD response and MCP-1 levels (R: 0.308, R2: 0.095, p: 0.044). Additionally, the low level of relationship was found between FMD response and MPV, MCP-1 and fibrinogen values (Table 2).

\section{DISCUSSION}

To best of our knowledge this is the first study about relationship between FMD response (impaired endothelial response) and blood parameters in patients with pRP. On the other hand this is the first report about relationship between impaired endothelial response and MCP-1 levels in pRP. Our results indicated that patients with pRP have higher impaired endothelial to ischemia. The incremental levels of serum WBC, MPV, MCP-1 and fibrinogen values were detected in pRP group. Moreover, moderate direct correlation was found between abnormal FMD response and serum MCP-1 values.

The impaired endothelial dysfunction demonstrated in both primary and secondary RP in previous studies. Furthermore it was shown that microvascular derangement was found as associated with endothelial dysfunction in RP patients ${ }^{11,12}$. The endothelium has an important role in the regulation of vascular response against blood flow-associated shear stress and ischemia-reperfusion events. Insufficient flow-mediated vasorelaxation response is an indicator for increased vascular disease ${ }^{13}$. The dilation response of the brachial artery after a 4-5 minutes ischemic period is a reliable non-invasive assessment method for the evaluation of endothelium functions. The post-ischemic brachial artery dilatation with equal to or more than $5 \%$ of normal diameter is accepted as normal endothelial functions. Additionally, dilatation with lower than $5 \%$ of diameter is accepted as impaired endothelial functions ${ }^{9,14}$. The FMD response was studied in patients with RP. Flavahan indicated as FMD response is normal in pRP and it was added that cold induced disruption of arteriovenous connections in RP cases, can lead to digital artery spasm ${ }^{15}$. Mavrikakis et al. studied FMD in patients with sRP and they detected abnormal FMD response in these patients. Additionally, they found that ascorbic acid does not reverse endothelial vasomotor dysfunction in their study ${ }^{16}$. Klein-Weigel et al. investigate the seasonal variations in patients with RP and they did not show abnormal FMD response in $\mathrm{pRP}^{17}$. However most of the previous reports were conducted with mall RP populations. Although our results indicated that abnormal FMD response can detected $5(17 \%)$ of 30 healthy individuals, the abnormal FMD was detected at $30(70 \%)$ of $43 \mathrm{pRP}$ patients.

The routine blood parameters were investigated for several kinds of vascular diseases ${ }^{18}$. Platelet indices were investigated in vasospastic disorders detected with cold stimulation test by Kadan et al. ${ }^{19}$. They found that the relationship between severity of disease and MPV. Shemirani et al. found independent relationship between $\mathrm{pRP}$ and higher serum MPV levels ${ }^{20}$. Another study higher MPV was suggested as triggering factor for $\mathrm{pRP}^{21}$. In same study WBC levels were found as insignificant predictor in same study. Lau et al. was found increased white blood cell activation in patients with $\mathrm{RP}^{22}$. Our findings supported that MPV and WBC levels in patients with pRP. Plasma fibrinogen is another laboratory parameter that investigated in vasospatic disorders. Splenger et al. concluded as increased plasma fibrinogen levels in patients with RP are related with disrupted distal microcirculation ${ }^{23}$. Similarly, higher fibrinogen levels found as associated with plasma fibrin clots displaying impaired lysability and increased endothelial damage in pRP by Żuk et 
al. ${ }^{24}$. In our study higher fibrinogen levels were detected in pRP patients.

MCP-1 is an important potent regulatory chemokine that is responsible for the migration and the infiltration of monocytes. The ischemia, oxidative stress, released cytokines, or growth factors triggers the biological activity of MCP-1 and leads to infiltration of monocytes/macrophages. Rajagopalan et al. investigated to MCP-1 levels in sRP and pRP and they found that MCP-1 levels were higher in sRP when compared with primary type. However, they did not compare the MCP-1 levels with healthy controls and did not investigate the relation with endothelial response ${ }^{25}$. MCP-1 was suspected to pathogenesis of vasospastic outcomes of diseases that presented with $\mathrm{sRP}^{26,27}$. However, the literature includes insufficient reports about the relationship between impaired endothelial function and MCP-1 levels in pRP. Furthermore, another insufficiency is about the differences between $\mathrm{pRP}$ and normal population in regards to MCP-1 levels. Our results indicated that MCP-1 levels are higher in patients with $\mathrm{pRP}$ and these results revealed a relation between impaired endothelial functions and serum MCP-1 levels.

In conclusion, our findings demonstrated that MPV, WBC, fibrinogen, and MCP-1 levels were higher in pRP patients when compare with healthy control. It seems to be that increased MCP-1 values were related to abnormal FMD response in pRP group. These results might be helpful for the establishment of the pathophysiology of the RP.

Limitations of Study

The main limitation of the study is concerning about small sample size. Although previous literature has present findings with smaller patient groups, the comprehensive cohorts are necessary for obtaining powerful and exact results. The second limitation is concerning the determination of endothelial response with a single method (FMD). The endothelial response should be confirmed with other techniques to present more clarified findings. The third limitation is related to the nature of the disease. If any underlying disease cannot be detected responsible for RP then it called primary RP. However, there is multifactorial etiology for RP and it is possible to skip diagnosis.

Acknowledgement

Funding: This research did not receive any specific grant from funding agencies in the public, commercial, or not-for-profit sectors.

Competing Interest: The authors declare no conflict of interest.

\section{REFERENCES}

1. Ingegnoli F, Ughi N, Crotti C, Mosca M, Tani C. Outcomes, rates and predictors of transition of isolated Raynaud's phenomenon: a systematic review and meta-analysis. Swiss Med Wkly. 2017;147:w14506. doi: 10.4414/smw.2017.14506.

2. Hughes M, Allanore Y, Chung L, Pauling JD, Denton CP, Matucci-Cerinic M. Raynaud phenomenon and digital ulcers in systemic sclerosis. Nat Rev Rheumatol. 2020;16(4):208-221. doi: 10.1038/s41584-020-03864 .

3. Galluccio F, Matucci-Cerinic M. Two faces of the same coin: Raynaud phenomenon and digital ulcers in systemic sclerosis. Autoimmun Rev. 2011;10(5):241-3. doi: 10.1016/j.autrev.2010.09.008.

4. Carlsson D, Wahlström J, Burström L, Hagberg M, Lundström R, Pettersson H, et al. Can sensation of cold hands predict Raynaud's phenomenon or paraesthesia? Occup Med (Lond). 2018;68(5):314-319. doi: 10.1093/occmed/kqy053. PMID: 29750280;

5. Temprano KK. A Review of Raynaud's Disease. Mo Med. 2016;113(2):123-6. PMID: 27311222;

6. Lambova SN, Müller-Ladner U. The role of capillaroscopy in differentiation of primary and secondary Raynaud's phenomenon in rheumatic diseases: a review of the literature and two case reports. Rheumatol Int. 2009;29(11):1263-71. doi: 10.1007/s00296-009-1019-z. 
7. Latuskiewicz-Potemska J, Chmura-Skirlinska A, Gurbiel RJ, Smolewska E. Nailfold capillaroscopy assessment of microcirculation abnormalities and endothelial dysfunction in children with primary or secondary Raynaud syndrome. Clin Rheumatol. 2016;35(8):1993-2001. doi: 10.1007/s10067-016-3340-8.

8. Corretti MC, Anderson TJ, Benjamin EJ, Celermajer D, Charbonneau F, Creager MA, et al. International Brachial Artery Reactivity Task Force. Guidelines for the ultrasound assessment of endothelial-dependent flow-mediated vasodilation of the brachial artery: a report of the International Brachial Artery Reactivity Task Force. J Am Coll Cardiol. 2002;39(2):257-65.

9. Karahan O, Manduz S, Bektasoglu G, Zorlu A, Turkdogan KA, Bozok S. A high oxidative stress index predicts endothelial dysfunction in young male smokers. Bratisl Lek Listy. 2013;114(12):721-5. doi: 10.4149/bll_2013_152.

10. Duman A, Turkdogan KA, Avcil M, Yenisey C, Ture M, Akoz A, et al. The predictive value of the inflammatory markers P-selectin and MCP1 in determining the length of stay and 30-day survival in the differentiation of sepsis patients. J Pak Med Assoc. 2018;68(9):1321-1326.

11. Le JH, Cho KI. Association between endothelial function and microvascular changes in patients with secondary Raynaud's phenomenon. Clin Rheumatol. 2014;33(11):1627-33. doi: 10.1007/s10067-014-2553-y.

12. Mosdósi B, Bölcskei K, Helyes Z. Impairment of microcirculation and vascular responsiveness in adolescents with primary Raynaud phenomenon. Pediatr Rheumatol Online J. 2018;16(1):20. doi: 10.1186/s12969018-0237-x.

13. Pyke KE, Tschakovsky ME. The relationship between shear stress and flow-mediated dilatation: implications for the assessment of endothelial function. J Physiol. 2005;568(Pt 2):357-69. doi: 10.1113/jphysiol.2005.089755.

14. Charakida M, Masi S, Lüscher TF, Kastelein JJ, Deanfield JE. Assessment of atherosclerosis: the role of flow-mediated dilatation. Eur Heart J. 2010;31(23):2854-61. doi: 10.1093/eurheartj/ehq340.

15. Flavahan NA. A vascular mechanistic approach to understanding Raynaud phenomenon. Nat Rev Rheumatol. 2015;11(3):146-58. doi: 10.1038/nrrheum.2014.195.

16. Mavrikakis ME, Lekakis JP, Papamichael CM, Stamatelopoulos KS, Kostopoulos ChC, Stamatelopoulos SF. Ascorbic acid does not improve endothelium-dependent flow-mediated dilatation of the brachial artery in patients with Raynaud's phenomenon secondary to systemic sclerosis. Int J Vitam Nutr Res. 2003;73(1):3-7. doi: 10.1024/0300-9831.73.1.3.

17. Klein-Weigel P, Krall K, Falkensammer J, Heinz-Erian P, Ulmer H, Fraedrich G. Lack of seasonal variation in flow-mediated dilatation of the brachial artery in women with primary Raynaud's phenomenon and healthy controls. Vasa. 2003;32(2):69-73. doi: 10.1024/0301-1526.32.2.69. 18. Karahan O, Yavuz C, Kankilic N, Demirtas S, Tezcan O, Caliskan A, et al. Simple blood tests as predictive markers of disease severity and clinical condition in patients with venous insufficiency. Blood Coagul Fibrinolysis. 2016;27(6):684-90. doi: 10.1097/MBC.0000000000000478.

19. Kadan M, Karabacak K, Kaya E, Arslan G, Erol G, Doğancı S, et al. Platelet indices may be correlated with severity of vasospastic disorders. Med Sci Monit Basic Res. 2015;21:63-7. doi: 10.12659/MSMBR.893999.

20. Shemirani AH, Nagy B Jr, Takáts AT, Zsóri KS, András C, Kappelmayer J, et al. Increased mean platelet volume in primary Raynaud's phenomenon. Platelets. 2012;23(4):312-6. doi: 10.3109/09537104.2011.618563.

21. Turan E, Kilic SS. Retrospective view of primary Raynaud's phenomenon in childhood. Reumatol Clin. 2019;15(6):e92-e95.doi: 10.1016/j.reuma.2017.12.012.

22. Lau CS, O'Dowd A, Belch JJ. White blood cell activation in Raynaud's phenomenon of systemic sclerosis and vibration induced white finger syndrome. Ann Rheum Dis. 1992;51(2):249-52. doi: 10.1136/ard.51.2.249. 
23. Spengler MI, Svetaz MJ, Leroux MB, Leiva ML, Bottai HM. Association between capillaroscopy, haemorheological variables and plasma proteins in patients bearing Raynaud's phenomenon. Clin Hemorheol Microcirc. 2004;30(1):17-24.

24. Żuk J, Snarska-Drygalska A, Malinowski KP, Papuga-Szela E, Natorska J, Undas A. Unfavourably altered plasma clot properties in patients with primary Raynaud's phenomenon: association with venous thromboembolism. J Thromb Thrombolysis. 2019;47(2):248-254. doi: 10.1007/s11239-019-01805-0.

25. Deshmane SL, Kremlev S, Amini S, Sawaya BE. Monocyte chemoattractant protein-1 (MCP-1): an overview. J Interferon Cytokine Res. 2009;29(6):313-26. doi: 10.1089/jir.2008.0027.

26. Rajagopalan S, Pfenninger D, Kehrer C, Chakrabarti A, Somers E, Pavlic R, et al. Increased asymmetric dimethylarginine and endothelin 1 levels in secondary Raynaud's phenomenon: implications for vascular dysfunction and progression of disease. Arthritis Rheum. 2003;48(7):1992-2000. doi: 10.1002/art.11060.

27. Yamamoto T, Nishioka K. Role of monocyte chemoattractant protein-1 and its receptor,CCR-2, in the pathogenesis of bleomycin-induced scleroderma. J Invest Dermatol. 2003;121(3):510-6. doi: 10.1046/j.15231747.2003.12408.x.

28. Bellando Randone S, George J, Mazzotta C, Guiducci S, Furst DE, Mor A, et al. Angiostatic and Angiogenic Chemokines in Systemic Sclerosis: An Overview. Journal of Scleroderma and Related Disorders. 2017;2(1):1-10. doi:10.5301/jsrd.5000226

Figure and Table Legends

Figure 1. The bruising on hand and foot in patients with pRP

Figure 2. The comparison of monocyte chemoattractant protein-1 (MCP1) values in normal and abnormal flow-mediated dilatation (FMD) groups.

Table 1. The comparison of demographic and laboratory variables in pRP and healthy control group

Table 2. The relation between laboratory parameters and abnormal flow-mediated dilatation (FMD)

Table 1. The comparison of demographic and laboratory variables in $\mathrm{pRP}$ and healthy control group

\begin{tabular}{|c|c|c|c|}
\hline Variables & Control N:30 & $\begin{array}{l}\text { Raynaud Phenomenon } \\
\text { N:43 }\end{array}$ & $\mathrm{p}^{\#}$ \\
\hline Female $\mathrm{n}(\%)$ & $22(73 \%)$ & $34(79 \%)$ & 0.772 \\
\hline Age $($ mean \pm SD $)$ & $27.17 \pm 8.01$ & $28.33 \pm 8,71$ & 0.565 \\
\hline Smoking $\mathrm{n}(\%)$ & $8(27 \%)$ & $19(44 \%)$ & 0.201 \\
\hline Abnormal FMD* n(\%) & $5(17 \%)$ & $30(70 \%)$ & 0.000 \\
\hline $\mathrm{WBC}^{* *}\left(10^{-3} / \mathrm{uL}\right)$ & $6.20 \pm 1.43$ & $7.64 \pm 1.73$ & 0.000 \\
\hline Hemoglobin $(\mathrm{g} / \mathrm{dL})$ & $13.46 \pm 1.06$ & $12.93 \pm 1.78$ & 0.148 \\
\hline Platelet Count $\left(10^{-3} / \mathrm{uL}\right)$ & $225.50 \pm 79.23$ & $250.91 \pm 74.67$ & 0.167 \\
\hline $\mathrm{MPV}^{* * *}(\mathrm{fL})$ & $8.36 \pm 0.96$ & $10.47 \pm 0.87$ & 0.000 \\
\hline Creatinine $(\mathrm{mg} / \mathrm{dL})$ & $0.85 \pm 0.17$ & $0.79 \pm 0.21$ & 0.232 \\
\hline $\mathrm{AST}^{+}(\mathrm{IU} / \mathrm{L})$ & $21.20 \pm 5.14$ & $25.60 \pm 9.77$ & 0.027 \\
\hline $\mathrm{ALT}^{++}(\mathrm{IU} / \mathrm{L})$ & $23.45 \pm 7.36$ & $26.12 \pm 12.94$ & 0.311 \\
\hline D-Dimer $(\%)$ & $1.25 \pm 1.15$ & $2.50 \pm 5.049$ & 0.185 \\
\hline Fibrinogen $(\mu \mathrm{g} / \mathrm{ml})$ & $258.94 \pm 89.74$ & $375.57 \pm 160.49$ & 0.000 \\
\hline $\mathrm{FAR}^{+++}(\%)$ & $88.38 \pm 66.85$ & $112.54 \pm 45.49$ & 0.090 \\
\hline $\operatorname{NLR}^{\&}(\%)$ & $9.44 \pm 11.26$ & $8.07 \pm 6.03$ & 0.501 \\
\hline Albumin $(\mathrm{g} / \mathrm{dL})$ & 3.3500 .38841 & 3.3279 .70561 & 0.579 \\
\hline $\operatorname{DDAR}^{\& \&}(\%)$ & $0.3819 \pm 0.37301$ & $0.9210 \pm 1.65428$ & 0.877 \\
\hline $\mathrm{MCP}^{@}{ }^{@}(\mathrm{pg} / \mathrm{ml})$ & $264.4342 \pm 71.12647$ & $332.4933 \pm 39.45015$ & 0.000 \\
\hline
\end{tabular}




\begin{tabular}{|c|c|c|c|}
\hline Variables & Control N:30 & $\begin{array}{l}\text { Raynaud Phenomenon } \\
\text { N:43 }\end{array}$ & $\mathrm{p}^{\#}$ \\
\hline $\begin{array}{l}\text { *FMD: flow mediated } \\
\text { dilatation. }{ }^{* *} \text { WBC: } \\
\text { white blood cell. } \\
{ }^{* * *} \text { MPV: main platelet } \\
\text { volume. }{ }^{+} \text {AST: } \\
\text { aspartate } \\
\text { aminotransferase. } \\
{ }^{++} \text {ALT: alanine } \\
\text { aminotransferase. } \\
{ }^{+++} \text {FAR: fibrinogen to } \\
\text { albumin ratio. }{ }^{\&} \text { NLR: } \\
\text { Neutrophil to } \\
\text { Lymphocyte ratio. } \\
\& \& \text { DDAR: D-dimer to } \\
\text { albumin ratio. } \\
{ }^{\circledR} \text { MCP1: monocyte } \\
\text { chemo-attractant } \\
\text { protein-1 }{ }^{\#} \text { p }<0.05 \text { is } \\
\text { considered as } \\
\text { statistically significant }\end{array}$ & $\begin{array}{l}\text { *FMD: flow mediated } \\
\text { dilatation. }{ }^{* *} \text { WBC: } \\
\text { white blood cell. } \\
\text { ***MPV: main platelet } \\
\text { volume. }{ }^{+} \text {AST: } \\
\text { aspartate } \\
\text { aminotransferase. } \\
++ \text { ALT: alanine } \\
\text { aminotransferase. } \\
{ }^{+++} \text {FAR: fibrinogen to } \\
\text { albumin ratio. }{ }^{\circ} \mathrm{NLR}: \\
\text { Neutrophil to } \\
\text { Lymphocyte ratio. } \\
\& \& \text { DDAR: D-dimer to } \\
\text { albumin ratio. } \\
{ }^{\circledR} \text { MCP1: monocyte } \\
\text { chemo-attractant } \\
\text { protein-1 }{ }^{\#} \text { p }<0.05 \text { is } \\
\text { considered as } \\
\text { statistically significant }\end{array}$ & $\begin{array}{l}\text { *FMD: flow mediated } \\
\text { dilatation. }{ }^{* *} \text { WBC: } \\
\text { white blood cell. } \\
\text { ***MPV: main platelet } \\
\text { volume. }{ }^{+} \text {AST: } \\
\text { aspartate } \\
\text { aminotransferase. } \\
++ \text { ALT: alanine } \\
\text { aminotransferase. } \\
{ }^{+++} \text {FAR: fibrinogen to } \\
\text { albumin ratio. }{ }^{\circ} \mathrm{NLR}: \\
\text { Neutrophil to } \\
\text { Lymphocyte ratio. } \\
\& \& \text { DDAR: D-dimer to } \\
\text { albumin ratio. } \\
{ }^{\circledR} \text { MCP1: monocyte } \\
\text { chemo-attractant } \\
\text { protein-1 }{ }^{\#} \text { p }<0.05 \text { is } \\
\text { considered as } \\
\text { statistically significant }\end{array}$ & $\begin{array}{l}\text { *FMD: flow mediated } \\
\text { dilatation. }{ }^{* *} \mathrm{WBC} \text { : } \\
\text { white blood cell. } \\
\text { ***MPV: main platelet } \\
\text { volume. }{ }^{+} \text {AST: } \\
\text { aspartate } \\
\text { aminotransferase. } \\
++ \text { ALT: alanine } \\
\text { aminotransferase. } \\
{ }^{+++} \text {FAR: fibrinogen to } \\
\text { albumin ratio. \& NLR: } \\
\text { Neutrophil to } \\
\text { Lymphocyte ratio. } \\
\text { \&\&DDAR: D-dimer to } \\
\text { albumin ratio. } \\
{ }^{\circledR} \text { MCP1: monocyte } \\
\text { chemo-attractant } \\
\text { protein- } 1 \text { \# }<0.05 \text { is } \\
\text { considered as } \\
\text { statistically significant }\end{array}$ \\
\hline
\end{tabular}

Table 2. The relation between laboratory parameters and abnormal flow-mediated dilatation (FMD)

MCP1*

$\mathrm{WBC}^{* *}$

$\mathrm{MPV}^{* * *}$

Fibrinogen

${ }^{\circledR}$ FMD: flow mediated dilatation. ${ }^{* *} \mathrm{WBC}$ : white blood cell. ${ }^{* * *} \mathrm{MPV}:$ main platelet volume. ${ }^{*} \mathrm{p}$ : Correlation is significant 

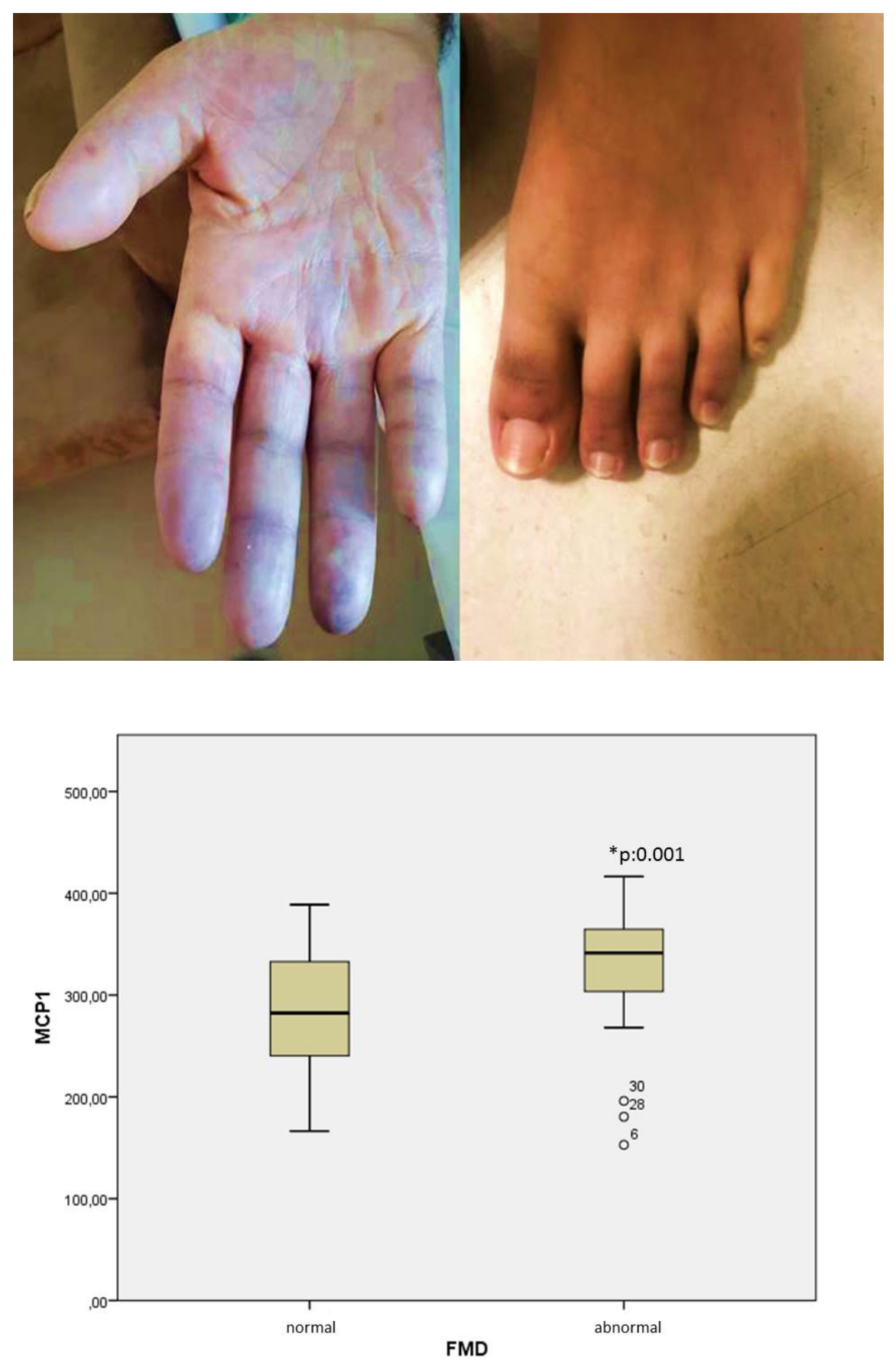